\title{
Enhancement of a District Heating Substation as Part of a Low-Investment Optimization Strategy for District Heating Systems
}

\author{
Anna Vannahme*D, Mathias Ehrenwirth and Tobias Schrag \\ Institute of New Energy Systems, University of Applied Sciences Ingolstadt, Esplanade 10, D-85049 Ingolstadt, \\ Germany; mathias.ehrenwirth@thi.de (M.E.); tobias.schrag@thi.de (T.S.) \\ * Correspondence: anna.vannahme@thi.de; Tel.: +49-841-9348-6484
}

Citation: Vannahme, A.; Ehrenwirth, M.; Schrag, T. Enhancement of a District Heating Substation as Part of a Low-Investment Optimization Strategy for District Heating Systems. Resources 2021, 10, 53. https:// doi.org/10.3390/resources10050053

Academic Editor: Ingo Leusbrock

Received: 29 March 2021

Accepted: 12 May 2021

Published: 19 May 2021

Publisher's Note: MDPI stays neutral with regard to jurisdictional claims in published maps and institutional affiliations.

Copyright: (C) 2021 by the authors. Licensee MDPI, Basel, Switzerland. This article is an open access article distributed under the terms and conditions of the Creative Commons Attribution (CC BY) license (https:// creativecommons.org/licenses/by/ $4.0 /)$.

\begin{abstract}
In an ongoing project, low-investment measures for the optimization of district heating systems are analyzed. The optimization strategies are collected in a catalog, which is the core of a guideline. The application of this guideline is demonstrated using two concrete district heating networks as examples. In this study, the improvement of an analog controlled district heating substation by an electronic controller is investigated. High supply temperatures and heat losses are often a challenge in district heating networks. The district heating substations have a major influence on the network return temperatures. The comparison of the two substation setups with analog and electronic controllers is carried out by laboratory measurement. It can be shown that the return temperatures can be reduced by an average of $20 \mathrm{~K}$ in winter and transition, as well as $16 \mathrm{~K}$ in summer. The district heating network losses are calculated for one of both specific district heating networks. They are calculated from the ratio of network losses to generated energy. The generated energy is the sum of network losses and consumer demand. The thermal losses of the network can be reduced by $3 \%$. The volume flow in the heating network can be reduced to a quarter. Therefore, the pumping energy requirement drops sharply since these changes cubically affect the volume flow.
\end{abstract}

Keywords: district heating substation; control; optimization; local district heating networks; non-retrofitted single-family houses; thermal test rig

\section{Introduction}

The presented study is in the context of the transformation of existing district heating networks (DHNs) into so called fourth generation DHNs' [1]. Some studies have described this transformation $[2,3]$. This transformation ensures the continued existence of DHNs in the future, as it aims for lower heat losses and allows the integration of low-temperature heat into DHNs, such as renewable-energy based heat sources or industrial excess heat. Sorknæs et al. [4] demonstrated the economic and energetic effect from third to fourth generation transition by considering Aalborg Municipality, Denmark as a case study area. The cost of the energy system was reduced by about 3\%, and total primary energy demand was reduced by $4.5 \%$, which was achieved as a result of the better integration of industrial waste heat and heat pumps to DHNs. Averfalk and Werner [5] pointed out that in the case of heat generation from geothermal energy, industrial excess heat, solar thermal energy and heat pumps, the influence of lower network temperatures on heat generation costs is distinctive.

Since lower network temperatures are a necessary prerequisite in order to use the aforementioned heat sources, various optimization approaches were investigated to reduce the return temperatures in DHNs. Table 1 summarizes the various optimization measures and their impact in order to reduce the return temperatures.

Basciotti et al. [6] investigated the influence of building renovation on the reduction of return temperatures. However, only a significant retrofitting rate (more than $80 \%$ of the 
buildings in the studied area) helped to bring down return temperature in the DHN up to $1.2{ }^{\circ} \mathrm{C}$. Köfinger et al. [7] examined the reduction by supplying new consumers with low system temperatures from the return flow of existing consumers with high system temperatures. In that scenario, consumers with a total heat demand of $630 \mathrm{MWh}$ were connected to an existing heating network with an annual demand of $2400 \mathrm{MWh}$. In this study, the return temperature could be reduced by $1.8^{\circ} \mathrm{C}$.

Other developments have revealed, including that both the optimal operation of the space heating system and the control strategy of the district heating substation (DHS) can positively contribute to an improvement of the overall efficiency. A new control method investigated by Gustafsson et al. [8] compared the previous heating control (based on the outdoor temperature) with a methodology that takes the primary supply temperature of the network into account. A larger temperature difference between flow and return was achieved by the control algorithm compensating for the variation in the outdoor temperature and the fluctuations in the supply temperature on the network side. The return temperature could be reduced by a maximum of up to $4.8^{\circ} \mathrm{C}$. Optimal control was developed for the consumer-side heating supply temperature and volume flow by van Oevelen et al. [9]. The secondary supply temperature was increased with a simultaneous reduction of the secondary volume flow. Using this method, the average return temperature in the high-temperature case dropped by $6{ }^{\circ} \mathrm{C}$. The authors also investigated the impact of oversized heating system design. They identified that with $100 \%$ oversizing, the return temperature can be decreased by $9.8^{\circ} \mathrm{C}$. Both measures together led to reductions in the return temperature of up to $18.2^{\circ} \mathrm{C}$. Tol et al. [10] developed a control strategy that allowed for the adoption of the feed temperature at the district level to the cooling performance of the consumer substation. Compared to the outside temperature-based control strategy, the new one led to less electricity power loss in the case of the cogeneration heat and power plant.

In order to increase the efficiency of DHNs, faults in customer stations have to be identified. A new fault detection method has been presented which works with the temperature difference signature [11]. The method presented is fast and inexpensive, and therefore feasible in practice. A field test in a Swedish district showed that $10 \%$ of substations were identified with temperature difference faults by on-site inspection, while $6 \%$ were detected by this method. Another method to identify faults in DHS is excess flow analyses [12]. Testing this method in the field estimates a return temperature reduction of $4{ }^{\circ} \mathrm{C}$ to $8{ }^{\circ} \mathrm{C}$, even though only typical errors such as calcified heat exchangers and missing check valves are fixed. Since reliable fault detection brings so much savings, research is being conducted on various approaches [13].

Table 1. Methods for lowering return temperatures.

\begin{tabular}{ccc}
\hline Optimization Measure & $\begin{array}{c}\text { Decreased Return } \\
\text { Temperatures }\end{array}$ & Reference \\
\hline $\begin{array}{c}\text { Retrofitting buildings } \\
\text { High- and low-temperature consumer cascade }\end{array}$ & $1.2^{\circ} \mathrm{C}$ & {$[6]$} \\
Heating supply temperature controlled by DHN feed & $1.8^{\circ} \mathrm{C}$ & {$[7]$} \\
temperature & $4.8^{\circ} \mathrm{C}$ & {$[8]$} \\
Heating control curves & $6{ }^{\circ} \mathrm{C}$ & {$[9]$} \\
Faulty detection of DHS and elimination of typical faults & $9.8^{\circ} \mathrm{C}$ & {$[9]$} \\
in DHS & $4{ }^{\circ} \mathrm{C}$ to $8{ }^{\circ} \mathrm{C}$ & {$[12]$} \\
\hline
\end{tabular}

The optimization of the design and hydraulics is also still progressing. In references $[14,15]$, various DHS constructions were identified for multifamily buildings in order to reduce the DHN return temperatures. A promising concept with a fresh water module and a serial-connected heat exchanger led to better cooling and has been described as economically feasible [14]. Elfner et al. [16,17] further developed the aforementioned concept 
for different heat generation plants, as well as building types and standards. In doing so, the return temperatures can be reduced and therefore the efficiency of the overall system can be significantly improved. For single-family houses (SFHs), the financial framework is too tight for more complex DHS systems. Therefore, the design of the DHS needs to be implemented by only a few components. The presented study shows that return temperatures can be reduced by $16^{\circ} \mathrm{C}$ to $20^{\circ} \mathrm{C}$ by means of an electronic controller with less expense. The study aims to show that a fundamental upgrade of the analogue standards in existing DHNs should always be considered. Since in these cases the DHN feed temperature is maintained, the capacity of the system is increased considerably so that further consumers can be connected. Otherwise, the volume flow drops profitably.

The results of this study will be transferable to a whole range of DHNs. Analog controlled DHSs with so called self-operated valves are quite common [18]. Between the end of the 1990s and the 2020s, more DHNs were built in Germany using the heat generated from the biomass combined heat and power process. The heat extracted from biomass cogeneration was often seen as a costless supplement to electricity generation. Therefore, the focus was not on heat use efficiency. With the ending of the Renewable Energies Act (EEG) subsidy after 20 years of operation, the focus is now shifting to the efficient use of heat. Therefore, this study will help some DHN operators to continue operating their DHNs more economically.

\section{Materials and Methods}

\subsection{Positioning of This Study in the Overall Context of the OREWA Project}

Improving DHNs with low-investment measures ensures their cost- and energyefficient operation in the future and is vital for energy transition. The ongoing research project 'OREWA' (optimization and restructuring of DHNs including evaluation of transferability, ecology, and economy) contains the collection of optimization measures in a catalog up to the application of these measures. The three methodical steps are illustrated in Figure 1.

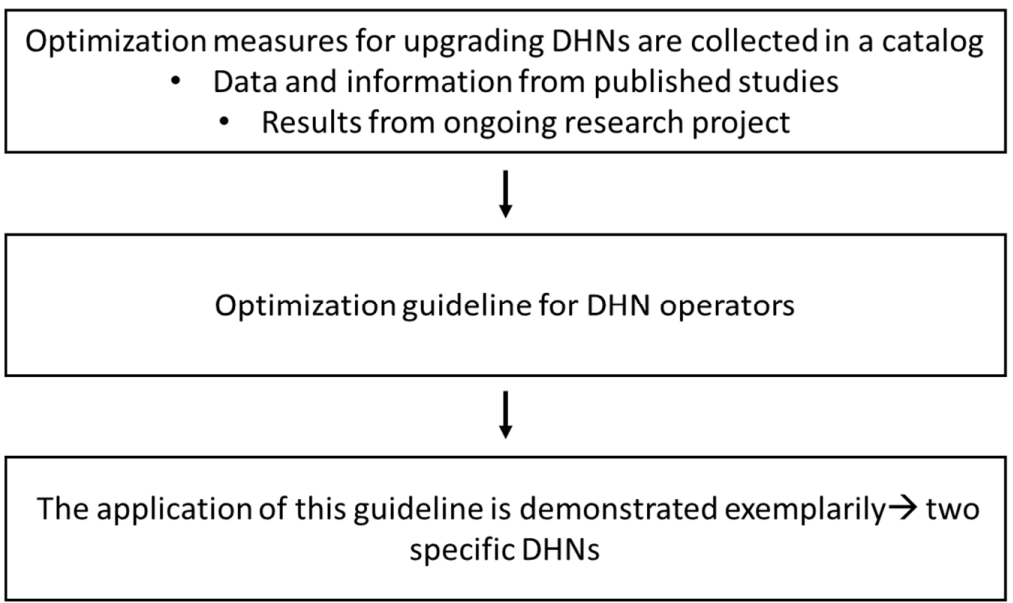

Figure 1. Methodology of the ongoing research project OREWA.

The first step of the OREWA project shown in Figure 1 involves collecting optimization measures from published studies and from the ongoing investigation. The catalog is intended to serve as a guideline for district heating operators. Based on typical DHN characteristics such as overall energy demand, heat density, network temperatures or key performance indicators like those defined in [19], the measures are extracted that can be useful and economical for a specific network. Thus, in the second step (cf. Figure 1), a selection process is implemented. The measurements which are identified to be sensible must be examined more closely for the operator's DHN. This procedure will be demonstrated in the third step using two exemplary DHNs. 
Within the third step, the presented investigation is to be placed, and the step will be shown exemplarily. For the specific DHNs, several measures from the catalog are eliminated because of their specific characteristics. The DHNs are small and have high heat losses and high DHN return temperatures. Therefore, the measures identified as beneficial are the upgrade of the substations and subsequently the reduction of the return temperatures. This paper focuses on the laboratory experiment used to determine the potential optimization of the DHS and thus for the district heating system. The results are then used to calculate the thermal savings via simulation. In addition, the cost of improving the substation must be calculated accurately.

\subsection{Objective of DHS Optimization}

Analysis of the specific DHNs showed that the difference between the supply and return temperatures of the DHNs is about $8 \mathrm{~K}$ on an annual average. Thus, the system is very inefficient. It was recognized that this is due to the analog controlled DHSs with so called self-operated valves. It was observed that high volume flows continuously flowed on the primary side of the substation, even in times with no demand. On the one hand, the everlasting volume flow is due to the kind of the controller; on the other hand, the high-volume flows are due to poor manual adjustment of the controller. The question is how to lower the return temperatures and enhance the controller. For this purpose, a few necessary requirements were considered for the new DHS controller:

- It should need as few parameters as possible and can be installed into the existing DHS;

- It should be built as a retrofitting module for each analog controlled existing DHS;

- It should be as simple and therefore inexpensive as possible;

- It should close the valve on the DHN side completely in times with no demand;

- It should be able to control the supply temperature on the heating system side. Thus, the return temperature will be lower, because the heating systems need only $60{ }^{\circ} \mathrm{C}$ for the supply temperature and not $70^{\circ} \mathrm{C}$, which is automatically set with the analog controller (see detailed description below);

- It should have a communication interface to the heating center. Firstly, this enables faults to be detected and secondly, further optimization, such as intermittent operating strategies, can be implemented.

Basically, the electronic controller requires two values for the valve opening degree (cf. Figure $2 \mathrm{~b}$ red circled valve). One is the maximum acceptable return temperature on the DHN side $\mathrm{T}_{\mathrm{DHN}}$ return limit and the other is the desired supply temperature on the secondary side $T_{\text {target sec. supply }}$. The actual values of $T_{D H N}$ return and $T_{\text {sec. supply }}$ are compared with the specified temperatures. Figure 3 displays the controller logic which is used to operate the primary side valve.

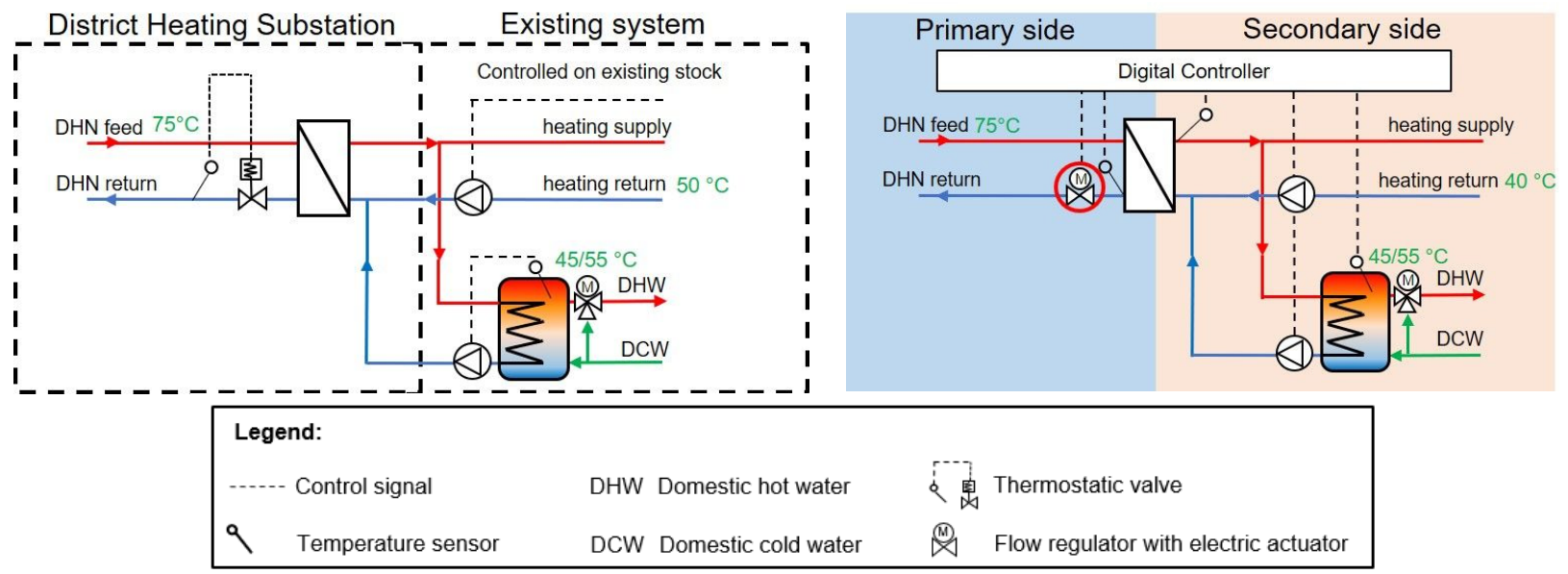

(a)

(b)

Figure 2. Setup of DHSs. (a) State-of-the-art setup. (b) Optimized setup. 


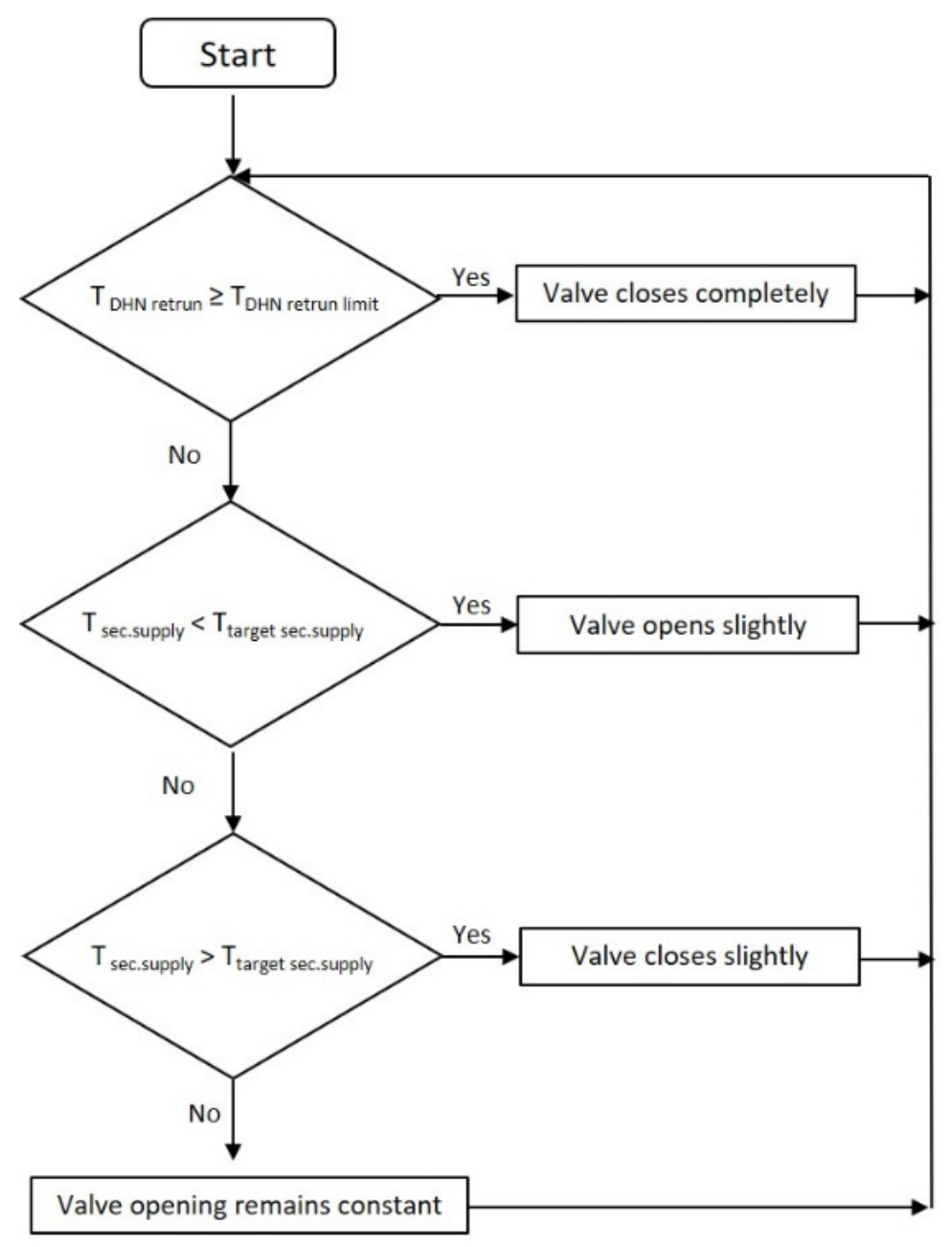

Figure 3. Block diagram for the control of the valve.

\subsection{Description of the State-of-the-Art and Optimized DHS Setup}

The DHS, which is installed in the two specific networks, is shown in Figure 2a. The part of the DHS setup from the DHN to heat exchanger is called the primary side. The domestic installation is referred to as the secondary side. Originally, the heating systems in such SFHs were supplied by oil boilers. By removing these oil boilers, the domestic hot water (DHW) storages, as well as the controllers of the pumps, were left independent from the new heat transfer components. In principle, the DHN is coupled into the existing house system via a plate heat exchanger and a thermostatic valve. The thermostatic valve is set to a target return temperature on the primary side (cf. Figure 2a). Fluid between the sensor and the valve expands to a greater or lesser extent proportionally to the DHN return temperature and thus determines the degree of opening of the valve. In the case of a low temperature in the DHW return pipe, the consumption by the consumer is assumed to be high. Subsequently, the fluid within the thermostat sensor contracts, allowing the valve to open further. If the demand is small or non-existent, i.e., the DHN return temperature is close to the DHN feed temperature, the valve almost closes completely. A permanent small opening of the valve is necessary for the proper functioning of the thermostatic valve. However, this leads to the fact that during times of low heat demand (e.g., summer), a small mass flow with high temperature permanently flows through the pipes, causing high thermal losses of the DHN. The thermostat DHS is an 'uncontrolled DHS', as the secondary side cannot be set to specific set points. As a result, the temperature on the secondary side solely depends on the temperature on the primary side. 
To overcome the aforementioned problems, the thermostatic valve is replaced by a flow controller with an additional electric actuator (cf. Figure $2 b$, red circled valve).

The automatic flow controller can be configured individually in each SFH to meet the maximum load agreed in the contract with the network operator. Configuration of the automatic flow controller allows for easier hydraulic balancing of the DHN. The particular advantage of this method is that the DHN can properly supply all consumers in the design case; even the consumers at the furthest point from the heating center receive the ordered power. In combination with the electric actuator, an electronic controller controls the flow. The required parameters are stored in the controller. Another advantage of the electronic controller is that central control from the heating center is possible. Depending on the given parameters, the controller can adjust the flow by means of the electric actuator. In case of no consumption, the valve is completely closed, therefore reducing the thermal losses of the DHN. At the same time, it is possible to separate the supply of the space heating system from charging the DHW storage. The particular advantage of such a DHW charging priority is that the storage tank can be charged as quickly as possible. The maximum load can be used for charging the storage tank. During the time when the storage tank is charged, the return temperatures are much higher than at times when only the heating is operated. Thus, a fast charging time keeps the time with high return temperatures as short as possible. This system is undoubtably more complex than the uncontrolled one. The electronic control requires a few settings, and the valve is dependent on auxiliary power.

To quantify the benefit of this setup, both DHSs were measured on a thermal test rig in the laboratory (cf. Figure 4).

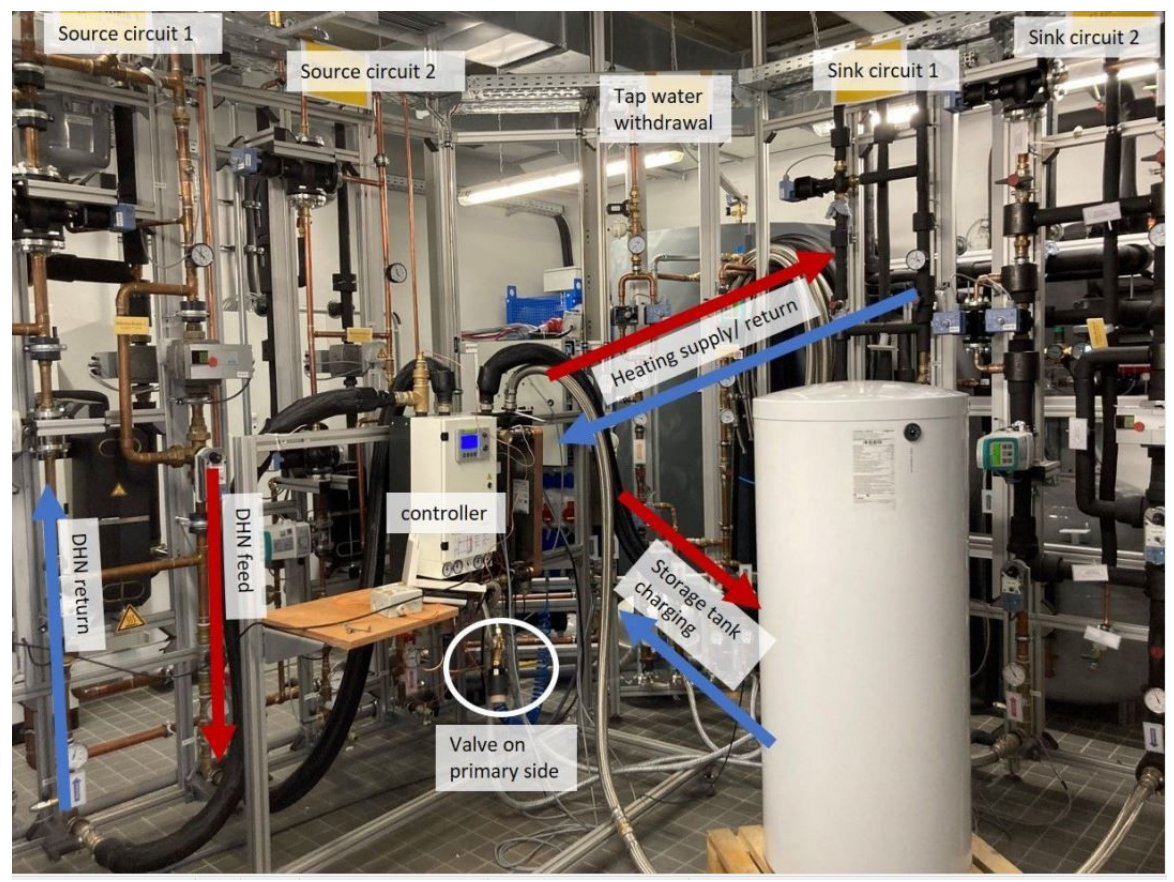

Figure 4. Photograph of the laboratory setup. The test rig had two source circuits and two sink circuits. The test object determines which ones are used (source: authors).

In the subsequent text, the following abbreviations are used for the systems:

- Thermostatically controlled DHS (ThermDHS);

- Electronically controlled DHS (ElecDHS).

The investigation was carried out by measurements in the laboratory. For this purpose, a thermal test rig was constructed (cf. Figure 5). All sensors and actuators were controlled and measured by software. Data acquisition devices connect the software and the hydraulic circuits. They transmit the values to the actuators and record the values from the sensors. 
The DHN, as well as the heating and tap water demand, are emulated with the hydraulic circuits of the test rig [20].

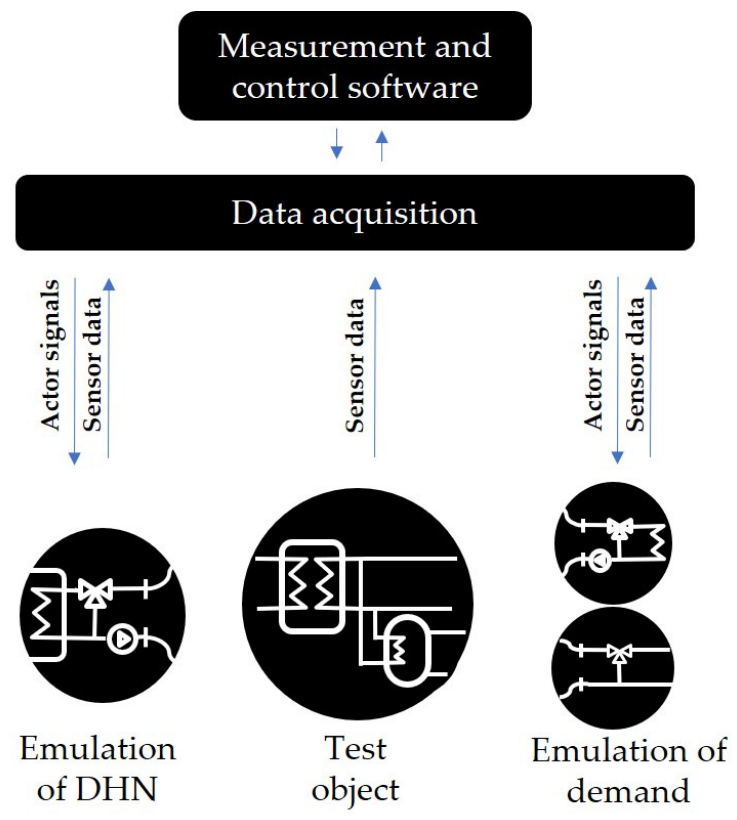

Figure 5. Scheme of the test rig.

The measurement of both DHSs takes place under the same consumer demand profiles. They are measured under a representative heating load profile of a winter day and a transition day [21]. In the case of the DHW demand, the same profile is used for winter, transition, and summer days. The measurement of each typical day means a $24 \mathrm{~h}$ measurement. The resolutions of the load profiles should be chosen in such a way that they provoke a realistic behavior of the DHS. Therefore, the resolutions worked out by [14] were chosen (cf. Table 2). A data acquisition unit recorded the measurement data every $2 \mathrm{~s}$. This ensures that peaks are detected as accurately as possible.

Table 2. Sufficient resolution of demand profiles.

\begin{tabular}{ccc}
\hline Profile & Sufficiently Accurate Resolution [14] & Reference \\
\hline Heat demand & $10 \mathrm{~min}$ & {$[21]$} \\
DHW demand & $10 \mathrm{~s}$ & {$[22]$} \\
\hline
\end{tabular}

The three measured typical days are used to calculate the values like return temperatures or DHN losses for one year (cf. Section 3.4.2).

In order to use representative load profiles, the heating profiles according to VDI 4655 were utilized [21]. The annual heating demand was determined from the typical demands (cf. Table 3).

Table 3. Typical yearly demand of SFH in the specific DHNs.

\begin{tabular}{cc}
\hline Part & Size \\
\hline Yearly heat demand & $26 \mathrm{MWh}$ \\
Full load utilization hours & $1700 \mathrm{~h}$ \\
Maximum load & $15 \mathrm{~kW}$ \\
\hline
\end{tabular}

For the DHW demand profiles, a load profile with a high resolution was used (cf. Table 2). In the case of the two investigated DHNs, an average of 3.4 people live 
in a household, which results in an average daily demand of $4.7 \mathrm{kWh}$. The values used as a basis for calculating the DHW demand are shown in Table 4.

Table 4. The basis for calculation of the DHW profile.

\begin{tabular}{cc}
\hline Part & Size \\
\hline Yearly DHW demand & $500 \mathrm{kWh}$ per person [21] \\
Numbers of persons per SFH & 3.4 \\
Daily energy demand & $4.7 \mathrm{kWh}$ \\
\hline
\end{tabular}

The temperature levels given in Table 5 were used as the basis for the measurements in the laboratory. The specific DHNs are both operated with constant supply temperatures of $75{ }^{\circ} \mathrm{C}$ all year round. A heating system design temperature of $60^{\circ} \mathrm{C} / 40^{\circ} \mathrm{C}$ is representative of the consumers in both existing DHNs according to the operator. However, the disadvantage with the ThermDHS is that the secondary side supply temperature cannot be determined. It depends directly on the DHN feed temperature. Thus, the supply temperature on the secondary side for this system is $70^{\circ} \mathrm{C}$.

Table 5. Given temperatures for the laboratory measurement.

\begin{tabular}{|c|c|c|c|}
\hline & & ThermDHS & ElecDHS \\
\hline Part & Name & \multicolumn{2}{|c|}{ Value } \\
\hline $\mathrm{DHN}$ & Feed temperature & \multicolumn{2}{|c|}{$75^{\circ} \mathrm{C}$ all seasons } \\
\hline Heating & Design temperatures & $70 / 50{ }^{\circ} \mathrm{C}$ & $60 / 40{ }^{\circ} \mathrm{C}$ \\
\hline DHW storage tank & Maximal and minimal temperatures & \multicolumn{2}{|c|}{$55^{\circ} \mathrm{C}, 45^{\circ} \mathrm{C}$} \\
\hline
\end{tabular}

The heat demand profiles were calculated for measurement in the laboratory with a constant supply and return temperature. As described, these are $60{ }^{\circ} \mathrm{C} / 40{ }^{\circ} \mathrm{C}$ for the ElecDHS and $70^{\circ} \mathrm{C} / 50{ }^{\circ} \mathrm{C}$ for the ThermDHS. Accordingly, the volume flows vary depending on the fluctuating demand.

In DHNs, a low maximum charging temperature of the storage tank is typically aimed for, as the return temperatures rise accordingly during charging. At the same time, lower charging temperatures can keep the calcification of the heat exchanger low [14]. Therefore, $55^{\circ} \mathrm{C}$ was used as the maximum storage temperature in the laboratory test. At this operating temperature, [23] requires that the water be completely replaced at least every three days. In practice, however, to prevent legionella, the DHW storage tanks are designed to replace the water once a day. With the electronic controller, however, the once-a-day heating up to and over $60^{\circ} \mathrm{C}$ can also be fulfilled. The temperature sensor is located at one-third of the way below the top of the storage tank. In the laboratory test, the storage tank in the DHS has a volume of $200 \mathrm{~L}$.

With the ElecDHS, the storage tank can be charged with priority. This means that the heating is off when the storage tank is charged. As a result, the supply temperature on the secondary side can be controlled independently from the supply temperature when the heating system is in operation.

As an outcome of the presented article, the energetic benefit of reducing the return temperatures is calculated for one of the two specific DHNs. Considering the energy demand of the circulation pump allows for an extrapolation of the electrical energy savings.

\section{Results and Discussion}

\subsection{Quality of Measurement Data}

To ensure sufficient quality of the measurement data, the same boundary conditions must be met during the measurement. This includes that the constant supply temperature on the primary side of $75{ }^{\circ} \mathrm{C}$ for the DHN emulation is met, as well as that the temperature decrease in the heating circuit corresponds to the setpoint of $40^{\circ} \mathrm{C}$ in case of ElecDHS and 
$50{ }^{\circ} \mathrm{C}$ in case of ThermDHS. All target temperatures are colored green in Figure 2. Likewise, the heating and DHW energy quantities purchased must correspond to the target values. The relative errors $\left(\delta_{\mathrm{x}}\right)$ describe the deviation from the target values (cf. Figure 6$)$, which are calculated according to Equation (1) [24].

$$
T_{\text {return }, n}=\frac{\sum_{i}^{n}\left(T_{\text {return }, i} \times \dot{m}_{\text {return }, i}\right)}{\sum_{i}^{n} \dot{m}_{\text {return }, i}}
$$
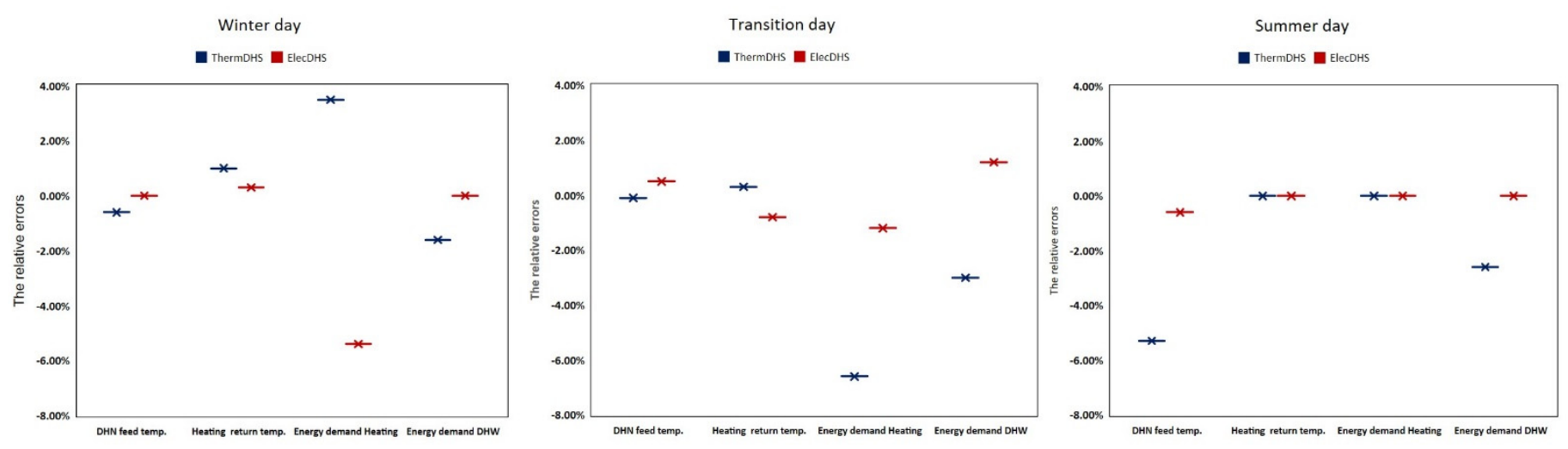

Figure 6. Deviation of the measured values from the target values.

The measured and target values for the heating energy demand differ because the target value for heating energy demand was calculated with a specific temperature difference. In practice, the temperature difference between the supply and return temperatures is slightly off. The deviations have not influenced the evaluated return temperature. It has a negligible impact on the required mass flow from the heating network. The measurement data can be validly compared.

\subsection{Resulting Return Temperatures}

The pure measured values are not compared, since the mass flow rates are temporarily different and have to be taken into account. Equation (2) shows the calculation of the weighted temperatures.

$$
T_{\text {return }, n}=\frac{\sum_{i}^{n}\left(T_{\text {return }, i} \times \dot{m}_{\text {return }, i}\right)}{\sum_{i}^{n} \dot{m}_{\text {return }, i}}
$$

where:

- $n$ : current time;

- $\quad i: 1$ to $n$, with step $=1$;

- $T_{\text {return, } n}$ : measured return temperature at the current time stamp;

- $T_{\text {return }, i}:$ measured return temperature at time stamp I;

- $\quad \dot{m}_{\text {return }, i}$ : measured mass flow rate at time stamp $i$.

With the thermostatically controlled DHS, it is noticeable that the DHN return temperature is much higher with the ElecDHS (cf. Table 6). This is due to the setting of the thermostat sensor. The setting of the sensor is based on summer operation. This means it reaches approximately $68^{\circ} \mathrm{C}$ when the supply temperature in summer is around $70^{\circ} \mathrm{C}$. It is set in such a way that a small volume flow always flows into the DHN when there is no demand. As a result, there is a relatively high-volume flow on the primary side in comparison to ElecDHS. 
Table 6. Results for the different DHS setups.

\begin{tabular}{|c|c|c|c|}
\hline Day & Parameter & ThermDHS & ElecDHS \\
\hline \multirow{4}{*}{ Winter } & DHN return temperature & $66^{\circ} \mathrm{C}$ & $46^{\circ} \mathrm{C}$ \\
\hline & Temperature difference between heating supply and return & $15.5 \mathrm{~K}$ & $13.7 \mathrm{~K}$ \\
\hline & Number of storage charging cycles & 4 & 10 \\
\hline & Average value of primary flow rate & $640 \mathrm{~L} / \mathrm{h}$ & $165 \mathrm{~L} / \mathrm{h}$ \\
\hline \multirow{4}{*}{ Transition } & DHN return temperature & $67^{\circ} \mathrm{C}$ & $48^{\circ} \mathrm{C}$ \\
\hline & Temperature difference between heating supply and return & $16.4 \mathrm{~K}$ & $15 \mathrm{~K}$ \\
\hline & Number of storage charging cycles & 4 & 8 \\
\hline & Average value of primary flow rate & $350 \mathrm{~L} / \mathrm{h}$ & $90 \mathrm{~L} / \mathrm{h}$ \\
\hline \multirow{3}{*}{ Summer } & DHN return temperature & $69^{\circ} \mathrm{C}$ & $53^{\circ} \mathrm{C}$ \\
\hline & Number of storage charging cycles & 2 & 2 \\
\hline & Average value of primary flow rate & $200 \mathrm{~L} / \mathrm{h}$ & $12 \mathrm{~L} / \mathrm{h}$ \\
\hline
\end{tabular}

With the electronically controlled DHS, it is possible to charge the storage tank and stop heating at the same time. This is useful because the storage is charged faster when all the available thermal power is used for charging only. The heating supply temperature is mixed with the colder water from the storage tank due to unwanted circulation (marking 5 in Figure 7). It mixes the storage tank temperature of around $50{ }^{\circ} \mathrm{C}$ with $60{ }^{\circ} \mathrm{C}$ of the supply temperature on the secondary side. With ElecDHS, the storage tank is recharged very frequently during periods with exclusive heating demand due to this unwanted circulation in the heating circuit. This is examined in more detail in the following paragraph. The electronically controlled DHS frequently recharging the storage tank is particularly disadvantageous. Charging the storage tank causes the otherwise low return temperatures to increase. During periods with heating demand only, these temperatures are around $41^{\circ} \mathrm{C}$ (heating return has an average temperature of $40^{\circ} \mathrm{C}$ ).

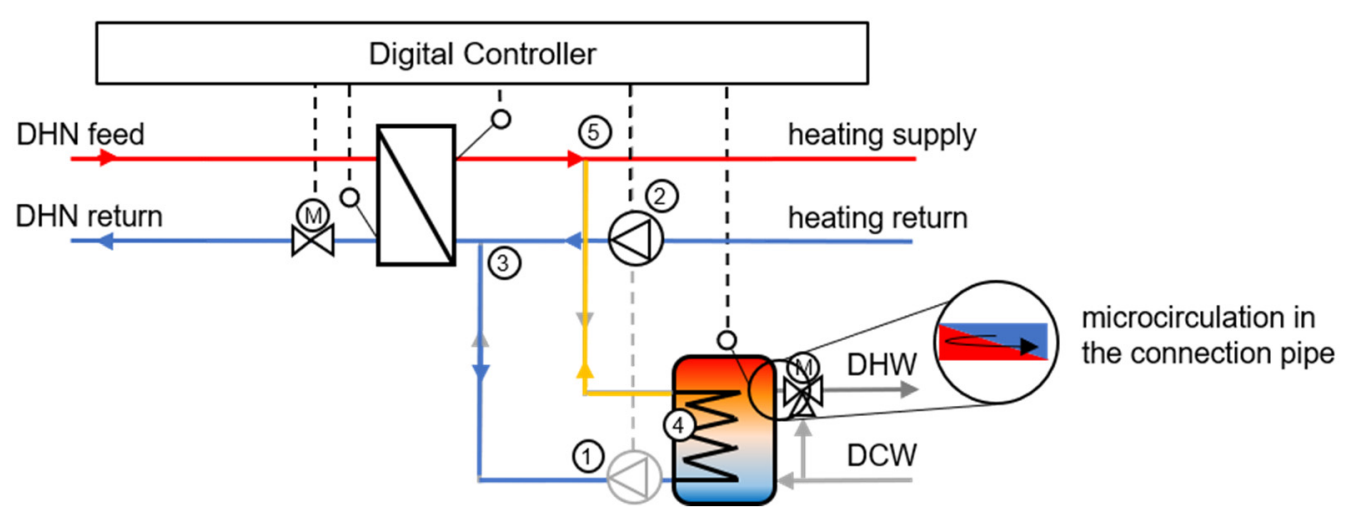

Figure 7. The storage tank is fully charged. The pump (1) is switched off. As the pump (2) is switched on to supply the space heating demand, the return flow of the heating passes the storage charging circuit in the opposite direction of the pump (3), causing the storage tank (4) to cool down. As a result, the mass flow mixes with the heating supply at point (5), subsequently cooling it down.

During the charging process of the storage tank, however, the average return temperatures were measured to be $53{ }^{\circ} \mathrm{C}$. The results for the transition day change in relation to the winter day because lower volume flows are sufficient to cover the heating demand. The lower volume flows also lead to a slightly more efficient temperature spread in the heating supply and return. Likewise, the lower volume flows lead to less unwanted circulation, which reduces the storage tank temperature. So, the storage tank only needs to be charged eight times during the day. However, it can be seen that the weighted return temperature during the storage tank charging cycles has a higher influence on the total return temperature for the day. This is because the flow rate of the primary side is very small during heating, since the demand is so low. The return temperature for the ThermDHS is quite high 
throughout the year. The storage tank is not discharged as much as with the ElecDHS due to the unwanted circulation. The reason for this is that the heating is inevitably operated at higher temperatures. The volume flows in the DHN are many times higher with the ThermDHS.

In summer, the return temperatures from the ThermDHS rise to $69^{\circ} \mathrm{C}$, as the DHW storage tank is not often charged. Significantly lower return temperatures of $53{ }^{\circ} \mathrm{C}$ can be achieved with the ElecDHS setup.

\subsection{Examination of Unwanted Circulation and Natural Convection}

The measurement of both DHSs reveals faulty circulation on the secondary side. The direction of the unwanted circulation is shown in Figure 7. The heating pump circulates the $40^{\circ} \mathrm{C}$ warm water $\left(50{ }^{\circ} \mathrm{C}\right.$ in case of the ThermDHS) from the heating system through the storage tank charging cycle. So, the $45^{\circ} \mathrm{C}$ to $55^{\circ} \mathrm{C}$ warm water inside the storage tank cools down. The field measurement data confirms this unwanted circulation flow.

In addition to the unwanted circulation, it can be observed that the storage tank cools down via the DHW and Domestic Cold Water (DCW) extraction pipes by natural convection. If there is no extraction, the DHW cools down via microcirculation (cf. Figure 7). This is a well-known problem with storage tank installations [25]. It can be avoided through siphons, heat traps, or check valves. Both phenomena-unwanted circulation and cooling through natural convection-have been verified by measurement data from the field. This ensures that these problems were not only caused by the test rig design (cf. Figure 8).

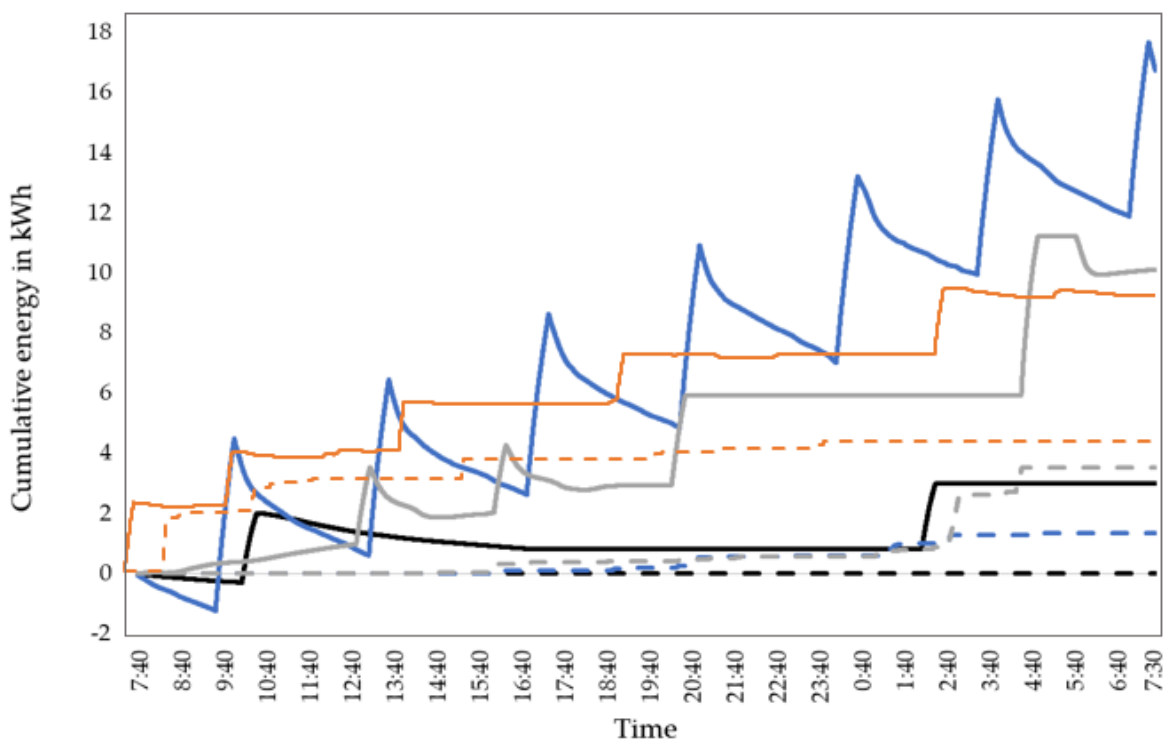

Field measurement

- Summer charge

- - Summer discharge

Winter charge

- -Winter discharge

—Transition charge

- - Transition discharg

Laboratory measurement

— Transition charge

- - - Transition discharge

Figure 8. The plots show the difference between extracted and stored energies on a specific day. The orange lines show that the laboratory measurement data are quite similar to those from the field measurement (grey lines).

The field measurement data show that the same phenomenon is observed in all seasons. In summer, the difference between stored and extracted energy is smaller as compared to the other seasons. This is because there are only losses caused by natural convection in summer. On transition days, the space heating demand and therefore the flow rate and consequently the faulty circulation volume flow is lower than on winter days. This means that the storage tank has to be recharged less often than in winter. The same result has been observed in the laboratory measurement. While the laboratory measured transition day (orange line) has five charging and four discharging processes, the day from the field measurement has four of both.

The balancing of the extracted and charged energies of a transition day measured in the laboratory with ThermDHS identified that $2.7 \mathrm{kWh}$ of the energy was lost due to natural convection. While, on other days, the energy loss was also measured as $2.7 \mathrm{kWh}$. Table 7 
represents the overview of the energy balancing of the storage tank. In total, $1.4 \mathrm{kWh}$ of energy extracted by the unwanted circulation is supplied to the heating.

Table 7. Balancing of the storage energy in $24 \mathrm{~h}$.

\begin{tabular}{cc}
\hline Part & Winter Day \\
\hline Incoming energy & $11 \mathrm{kWh}$ \\
Discharging through unwanted circulation & $1.4 \mathrm{kWh}$ \\
Extracted energy for DHW & $4.5 \mathrm{kWh}$ \\
Net energy stored in the storage at the end of the day & $1.5 \mathrm{kWh}$ \\
Standby losses & $0.9 \mathrm{kWh}$ \\
Energy losses through natural convection & $2.7 \mathrm{kWh}$ \\
\hline
\end{tabular}

A large amount of heat can be saved by preventing natural convection (cf. Table 8). Consumers pay nothing for the energy that is lost again through natural convection. However, more frequent storage tank charging with the ElecDHS results in higher return temperatures. Therefore, it is a disadvantage for the DHN operator. A DHN with 40 SFHs would save around $40 \mathrm{MWh}$ per year. Therefore, almost two more SFHs could be supplied.

Table 8. Losses through natural convection.

\begin{tabular}{cc}
\hline Part & Thermal Losses \\
\hline In 24 h per SFH & $2.7 \mathrm{kWh}$ \\
Per SFH and year & $1.0 \mathrm{MWh}$ \\
DHN with 40 SFH per year & $40 \mathrm{MWh}$ \\
\hline
\end{tabular}

To avoid the temperature loss of the storage caused by the DHW outlet pipes and the unwanted circulation, an ElecDHS improvement was investigated. The aim was to determine whether optimization of the house-side hydraulics was worthwhile. Therefore, the advantages and disadvantages of preventing descripted phenomena will be examined. In the improved version, the storage tank charging pipes are secured by check valves that prevent unwanted circulation. In addition, heat traps avoid the storage tank discharge via microcirculation. The improved DHS, named ElecDHS imp, was measured in the same way as the others. Table 9 shows the weighted return temperatures in comparison to ElecDHS.

Table 9. Results for the different DHS setups.

\begin{tabular}{|c|c|c|c|}
\hline Day & Parameter & ElecDHS & ElecDHS imp \\
\hline \multirow{4}{*}{ Winter } & DHNreturn temperature & $46^{\circ} \mathrm{C}$ & $42.2^{\circ} \mathrm{C}$ \\
\hline & Temperature difference between heating supply and return & $13.7 \mathrm{~K}$ & $17 \mathrm{~K}$ \\
\hline & Number of storage charging cycles & 10 & 2 \\
\hline & Average value of primary flow rate & $165 \mathrm{~L} / \mathrm{h}$ & $157 \mathrm{~L} / \mathrm{h}$ \\
\hline \multirow{4}{*}{ Transition } & DHN return temperature & $48^{\circ} \mathrm{C}$ & $42.2^{\circ} \mathrm{C}$ \\
\hline & Temperature difference between heating supply and return & $15 \mathrm{~K}$ & $18 \mathrm{~K}$ \\
\hline & Number of storage charging cycles & 8 & 2 \\
\hline & Average value of primary flow rate & $90 \mathrm{~L} / \mathrm{h}$ & $70 \mathrm{~L} / \mathrm{h}$ \\
\hline \multirow{2}{*}{ Summer } & DHN return temperature & $53^{\circ} \mathrm{C}$ & $53^{\circ} \mathrm{C}$ \\
\hline & Number of storage charging cycles & 2 & 2 \\
\hline
\end{tabular}

It is clearly visible that the ElecDHS imp achieves significantly fewer storage tank charging processes and, therefore, also lower return temperatures. The average return temperature is about $4{ }^{\circ} \mathrm{C}$ to $6{ }^{\circ} \mathrm{C}$ lower in winter and transition. With the number of typical days given in [21], an annual average of $3.6^{\circ} \mathrm{C}$ lower return temperature can be expected. In addition, the temperature spread between the heating supply and return is higher due to the elimination of the unwanted circulation. However, the three-way valve 
and thus the open connection between the storage tank circuit and the heating circuit in the ElecDHS is not only a disadvantage. The storage tank reduces the level of power peaks that have to be covered by the DHN (cf. Figure 9). If the heating system requests heat, a certain portion is immediately provided by the storage tank. In this way, the DHW storage tank operates as a kind of buffer storage. To analyze this impact, the 43,200-time steps that occur for a day with a resolution of two seconds are divided into different power levels, revealing that the ElecDHS imp more frequently leads to higher services from the DHN. This affects the annual duration curve of the overall system. In order to investigate the impact in terms of energy supply, a simulation will be necessary.

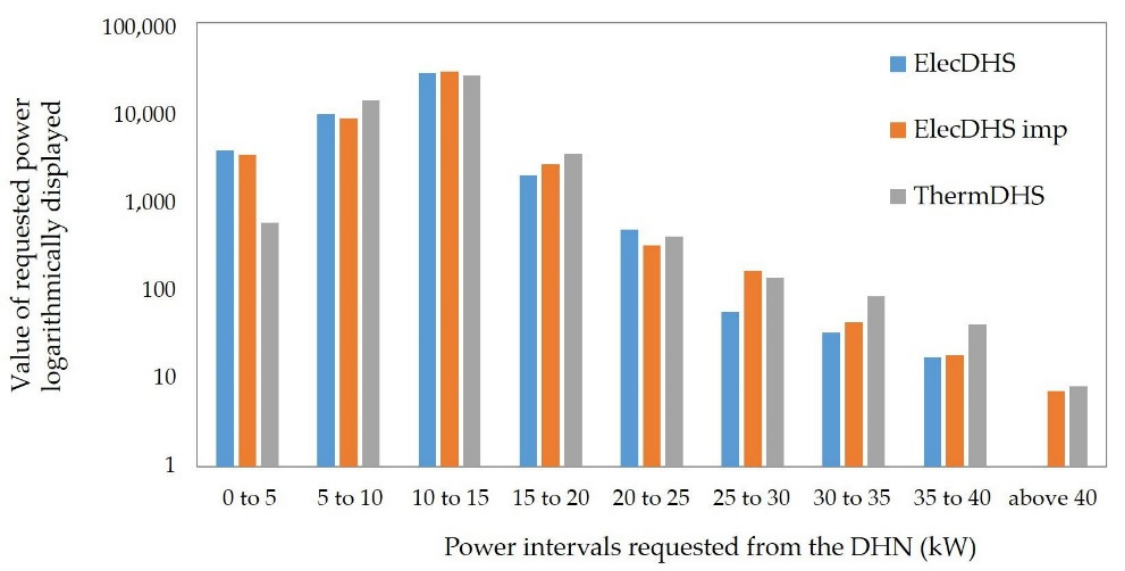

Figure 9. The difference in requested power from DHN.

ThermDHS has the highest power requirements compared to the other two DHSs. The DHN itself must cover the $70^{\circ} \mathrm{C}$ heating supply temperature. The storage tank with around $50{ }^{\circ} \mathrm{C}$ cannot compensate for this, as with the ElecDHS. The ElecDHS reaches only $60{ }^{\circ} \mathrm{C}$ for heating supply temperature.

\subsection{Energy Savings Due to Lower Return Temperatures}

3.4.1. Reduction of Electrical Pump Power

The higher spread between primary feed and return temperature is also accompanied by a DHN volume flow reduction. A lower volume flow is associated with a lower pressure drop, which also reduces the pump energy requirement. In order to estimate the savings, the average volume flow requirement of a consumer is calculated from the measured volume flow of the typical days. Table 10 shows the volume flows of each measured DHS and the calculation of energy savings.

Table 10. Electrical pump power cost due to mass flow rate reduction.

\begin{tabular}{cccc}
\hline & ThermDHS & ElecDHS & ElecDHS Imp \\
\hline Average volume flow per year one consumer & $443 \mathrm{~L} / \mathrm{h}$ & $102 \mathrm{~L} / \mathrm{h}$ & $92 \mathrm{~L} / \mathrm{h}$ \\
$k^{3}=\frac{P_{\text {ElecDHS or ElecDHS imp }}}{P_{\text {Therm DHS }}}$ & & $1.3 \%$ & $0.9 \%$ \\
\hline
\end{tabular}

The necessary electrical power for the pump is calculated as follows [26]:

$$
P_{P_{-} E l e c D H S}=\frac{\dot{V}_{E l e c D H S} \cdot \Delta p_{E l e c D H S}}{\eta_{P}},
$$

where:

- $\quad P_{P}$ : pump power;

- $\dot{V}$ : volume flow; 
- $\Delta p$ : pressure drops;

- $\eta_{p}:$ pump efficiency.

$$
\Delta p=\frac{L \cdot \lambda \cdot \rho}{2 \cdot d \cdot A^{2}} \cdot \dot{V}^{2}
$$

where:

- $\quad L, d, A$ : length, diameter and surface of the pipes;

- $\lambda$ : friction loss ratio;

- $\rho$ : density of water.

If:

$$
\dot{V}_{\text {ElecDHSopt }}=k \cdot \dot{V}_{\text {ElecDHS }}
$$

then it follows from (4) and (5) that:

$$
\frac{\Delta p_{\text {ElecDHS imp }}}{\Delta p_{\text {ElecDHS }}}=\left(\frac{\dot{V}_{\text {ElecDHS imp }}}{\dot{V}_{\text {ElecDHS }}}\right)^{2}=k^{2},
$$

And, consequently [27]:

$$
P_{P_{-} E l e c D H S \text { imp }}=\frac{\dot{V}_{\text {ElecDHS imp }} \cdot \Delta p_{\text {ElecDHS imp }}}{\eta_{P}}=\frac{k \cdot \dot{V}_{\text {ElecDHS }} \cdot k^{2} \cdot \Delta p_{\text {ElecDHS }}}{\eta_{P}}=k^{3} \cdot P_{P_{-} E l e c D H S}
$$

The calculation is only an estimation due to the inaccuracies caused by the average volume flow per year. As pumps are already installed and are only efficient in a certain range of volume flow, the indicated power consumption is only a theoretical one.

\subsubsection{Reduction of Thermal Losses}

One of the specific DHNs for which this optimization was investigated has a length of only $3.3 \mathrm{~km}$. Both UNO and DUO pipes are installed. The investigated DHN currently has heat losses of $35 \%$ in terms of the generated energy. The ElecDHS setup will reduce the thermal losses by 3\%. In return, two to three more SFHs can be connected. The improvement on the secondary side does not have a strong impact on the reduction of the DHN losses. Table 11 shows the heat losses in absolute numbers and as a percentage of the generated energy.

Table 11. Thermal losses calculated with the weighted temperatures for a year.

\begin{tabular}{cccc}
\hline & ThermDHS & ElecDHS & ElecDHS imp \\
\hline Absolute thermal losses & $439 \mathrm{MWh}$ & $375 \mathrm{MWh}$ & $366 \mathrm{MWh}$ \\
Relative thermal losses & $35 \%$ & $32 \%$ & $31 \%$ \\
\hline
\end{tabular}

A rough estimate of the heat losses can be obtained using Equation (8). A more accurate calculation of the heat losses will be carried out by means of simulation.

$$
T_{\text {mean }}=\frac{T_{\text {feed }}+T_{\text {return }}}{2}-T_{\text {soil }}
$$

where:

- $T_{\text {soil }}$ : average yearly soil temperature of $10^{\circ} \mathrm{C}$;

- $\quad T_{\text {return }, n}$ : DHN return temperature (see Tables 6 and 9);

- $T_{\text {return, }, i}$ : DHN feed temperature is about $75^{\circ} \mathrm{C}$.

By lowering only the return temperature, the DHN mean temperature drops by 6 to $10 \mathrm{~K}$, depending on the season. This observation refers to the differences between the ThermDHS and ElecDHS setup. 


\subsection{Discussion}

The thermostatic controller is not an appropriate device for substations in energyefficient buildings with lower heating standard temperatures. The supply temperature on the secondary side is not determinable unless a mixer is installed in the heating circuit. An advantage is that this controller needs no auxiliary power. The following disadvantages were identified:

- Higher peak power requested from DHN than the other setups;

- Permanent volume flow from DHN;

- Permanent high return temperatures.

The electric controller provides an important advantage. It can also be used to establish communication with the heating center. This allows for monitoring of the charging level of the storage tanks. As a result, the storage tanks can be charged at certain times, so that heat generation and pipelines of the heating network are more regularly utilized. In addition, the following advantages have been identified:

- Significant reduction in the average annual volume flow on the DHN side;

- High return temperatures only when the storage tank is being charged;

- Possibility to change DHN feed temperatures depending on the time of year; this is only possible with the ThermDHS, because the controller is set to a certain return temperature range;

- Adjustable supply temperature on the secondary side;

- Hydraulic balancing of the DHN.

In summer, the relative thermal losses of conventional DHNs are particularly high, because the consumption is so low. Therefore, the reduction of the return temperatures by the ElecDHS is considered as a great benefit. The thermal losses in relation to the generated energy decrease by $3 \%$ with the ElecDHS. This means that two to three more SFHs could be connected to this specific DHN. Economically, this is definitely advantageous for the DHN operator. For the homeowners, this implies, on the one hand, an investment in the ElecDHS, and, on the other hand, a decrease in heat prices. This is due to more consumers of the DHN and a lower amount of heat production. However, the optimization reduces not only the DHN losses, but also the pump energy costs. The pumping energy demand was calculated using the average yearly volume flows. Thus, it is an approximate extrapolation. By changing the DHS from thermostatically controlled to electronically controlled, the electrical energy for the circulating pump decreases significantly. The reduction of the volume flow leads to a substantially lower electrical energy requirement.

The optimization by the ElecDHS imp lowers the return temperatures of the DHN by an annual average of $3.6^{\circ} \mathrm{C}$. This does not achieve a striking improvement in terms of saving DHN losses. The prevention of natural convection can save about $4 \%$ of a household's heating energy per year. The extrapolation of the reduction for an entire DHN also shows that improvements can be profitable here.

In order to reduce the heat losses even further, the feed temperatures of the specific DHN must be reduced. An outdoor temperature-dependent supply temperature control will be analyzed, as well as an intermittent operating strategy. Since several users in these specific DHNs have decentral solar thermal energy systems, it will be investigated if some parts of the DHN can be kept cold in summer.

\section{Conclusions}

In a laboratory measurement, the benefits of upgrading an analog controlled substation with an electronic controller were investigated. This was studied for a specific DHS, but the controller is quite typical for DHSs in third generation DHNs. It was investigated whether the return temperatures of the DHN could be significantly reduced with the help of an electronic controller. The result is that the return temperature and the mass flow rate can be noticeably reduced with little effort. The laboratory measurement revealed that heat losses are decreased by $15 \%$ when ElecDHS is used instead of ThermDHS. Therefore, it makes 
sense to continue the investigation and determine the costs, since a good benefit can be achieved with a low-cost investment. Since the operation of DHNs is a highly dynamic process, a simulation is necessary to calculate the reduction in thermal losses. A simulation model also allows for the calculation of different scenarios, for example, to reduce the feed temperature of the DHN in preference to lowering the mass flow rate.

Author Contributions: Conceptualization, A.V., T.S.; methodology, A.V., M.E., T.S.; formal analysis, A.V.; investigation, A.V.; data curation, A.V.; writing-original draft preparation, A.V.; writingreview and editing, A.V., M.E., T.S.; visualization, A.V.; supervision, M.E., T.S.; project administration, A.V., M.E., T.S.; funding acquisition, A.V., M.E., T.S. All authors have read and agreed to the published version of the manuscript.

Funding: This research was funded by the German Bundesministerium für Wirtschaft und Energie (BMWi)/Projektträger Jülich (PtJ), grant number FKZ: 03EN3005. The APC was funded by the German Bundesministerium für Wirtschaft und Energie (BMWi).

Institutional Review Board Statement: Not applicable.

Informed Consent Statement: Not applicable.

Data Availability Statement: Not applicable.

Acknowledgments: Thanks to Enerpipe $\mathrm{GmbH}$ for providing us with the necessary DHS. Thanks to Girish Manjunath Jadhav for the support in programming and Jonas Busch for the construction of the test rig.

Conflicts of Interest: The authors declare no conflict of interest.

\section{References}

1. Lund, H.; Werner, S.; Wiltshire, R.; Svendsen, S.; Thorsen, J.E.; Hvelplund, F.; Mathiesen, B.V. 4th Generation District Heating (4GDH). Energy 2014, 68, 1-11. [CrossRef]

2. Averfalk, H.; Werner, S.; Felsmann, C.; Rühling, K.; Wiltshire, R.; Svendsen, S. Transformation Roadmap from High to Low Temperature District Heating Systems: Annex_XI Final Report; International Energy Agency: Paris, France, 2017.

3. Li, H.; Nord, N. Transition to the 4th generation district heating-possibilities, bottlenecks, and challenges. Energy Procedia 2018, 149, 483-498. [CrossRef]

4. Sorknæs, P.; Østergaard, P.A.; Thellufsen, J.Z.; Lund, H.; Nielsen, S.; Djørup, S.; Sperling, K. The benefits of 4th generation district heating in a 100\% renewable energy system. Energy 2020, 213, 119030. [CrossRef]

5. Averfalk, H.; Werner, S. Economic benefits of fourth generation district heating. Energy 2020, 193, 116727. [CrossRef]

6. Basciotti, D.; Köfinger, M.; Marguerite, C.; Terreros, O.; Agugiaro, G.; Schmidt, R.R. Methodology for the Assessment of Temperature Reduction Potentials in District Heating Networks by Demand Side Measures and Cascading Solutions. In Proceedings of the 12th REHVA World Congress CLIMA 2016, Aalborg, Denmark, 22-25 May 2016.

7. Köfinger, M.; Basciotti, D.; Schmidt, R.-R. Reduction of return temperatures in urban district heating systems by the implementation of energy-cascades. Energy Procedia 2017, 116, 438-451. [CrossRef]

8. Gustafsson, J.; Delsing, J.; van Deventer, J. Improved district heating substation efficiency with a new control strategy. Appl. Energy 2010, 87, 1996-2004. [CrossRef]

9. Van Oevelen, T.; Vanhoudt, D.; Salenbien, R. Evaluation of the return temperature reduction potential of optimized substation control. Energy Procedia 2018, 149, 206-215. [CrossRef]

10. Bergstraesser, W.; Hinz, A.; Braas, H.; Orozaliev, J.; Vajen, K. Lessons learned from excess flow analyses for various district heating systems. Smart Energy 2021, 1, 100005. [CrossRef]

11. Tol, H.I.; Desmedt, J.; Salenbien, R. A novel demand-responsive control strategy for district heating systems, featuring return temperature reduction. Energy Built Environ. 2021, 2, 105-125. [CrossRef]

12. Gadd, H.; Werner, S. Achieving low return temperatures from district heating substations. Appl. Energy 2014, 136, 59-67. [CrossRef]

13. Hamilton-Jones, M.; Schrammel, H. District Heating Fault Detection using Clustering Algorithms. In Proceedings of the 14th Sustainable Development of Energy, Water and Environment Systems Conference, Dubrovnik, Croatia, 1-7 October 2019.

14. Stadtwerke München; Hochschule für Angewandte Wissenschaften München; Ebert-Ingenieure. Breitenanwendung von Niedertemperatur-Systemen als Garanten für eine nachhaltige Wärmeversorgung: LowEx-Systeme: Abschlussbericht zum Forschungsvorhaben: LowEx-Fernwärme-Systeme im Rahmen des Förderkonzeptes EnEff:Wärme-Forschung für energieeffiziente Wärme-und Kältenetze; Stadtwerke München: München, Germany, 2014.

15. Szablinski, D. Energetische Optimierung von Solar Unterstützten Nahwärmesystemen; LEE: Bochum, Germany, 2005; ISBN 3934951120. 
16. Elfner, J.; Zeisberger, J.; Zielger, F.J. Entwicklung und Optimierung Hocheffizienter Trinkwassererwärmungssysteme für Wohn und Hotelgebäude (HochEff-TWE): Im Rahmen des Förderkonzeptes EnOB-Energieoptimiertes Bauen; Abschlussbericht zum Forschungsvorhaben BMWi 03ET1283A. 2020. Available online: https://w3-mediapool.hm.edu/mediapool/media/fk05/ fk05_lokal_1/fk05vs/forschung_und_entwicklung/publikationen_prof_dr_franz_josef_ziegler/2020_06_09_03ET1283A_ Abschlussbericht_final.pdf (accessed on 12 May 2021).

17. Elfner, J.; Ziegler, F.J. Improving thermal energy storage capacity and flexibility of residential energy systems by return flow optimization: A field test. In Proceedings of the ECOS 2020-The 33rd International Conference on Efficiency, Cost, Optimization, Simulation and Enviornmental Impact of Energy Systems 2020, Osaka, Japan, 3 July 2020.

18. Schuster, S.; Bücker, D. Key Performance Indicators for Thermal Energy Storage in District Heating Systems. Short-term Thermal Energy Storages. In Euroheat \& Power; VDE Verlag: Berlin, Germany, 2018.

19. Busch, J.; Schrag, T. Planning and implementation of a thermodynamic hydraulic Hardware-in-Loop testing rig for heat-pumps and heat transfer stations. Planning process and first steps of implementation. In Proceedings of the Applied Research Conference ARC, Glasgow, Scotland, 30 November-1 December 2017; pp. 268-295.

20. VDI-Gesellschaft für Energie und Umwelt. Referenzlastprofile von Ein- und Mehrfamilienhäusern für den Einsatz von KWK-Anlagen; Verein Deutscher Ingenieure e. V.: Düsseldorf, Germany, 2008.

21. Lange, M.; Zobel, M. Schlussbericht zum Vorhaben: Erstellung neuer Referenzlastprofile zur Auslegung, Dimensionierung und Wirtschaftlichkeitsberechnung von Hausenergieversorgungssystemen mit dem Akronym NOVAREF: Im Rahmen der Fördermaßnahme: Transfer von Forschungs- und Entwicklungsergebnissen (FuE) durch Normung und Standardisierung. 2017. Available online: http:/ / www.gbv.de/dms/tib-ub-hannover/890929130.pdf (accessed on 12 May 2021).

22. German Institute for Standardization. DIN 1988-Technische Regeln für Trinkwasser-Installationen-Teil 200: Installation Typ A (geschlossenes System)-Planung, Bauteile, Apparate, Werkstoffe; German Institute for Standardization: Berlin, Germany, 2012.

23. Haug, A.; Haug, F. Angewandte Elektrische Meßtechnik: Grundlagen, Sensorik, Meßwertverarbeitung, 2, Verbesserte Auflage; Vieweg+Teubner Verlag: Wiesbaden, Germany, 1993.

24. ESBE No.1 in Hydronic System Control. Heat Traps in Installations. Available online: https://www.esbe.eu/it/en/news/havewe-forgotten-to-make-heat-traps (accessed on 25 January 2021).

25. Konstantin, P. Praxisbuch der Fernwärmeversorgung; Springer: Berlin/Heidelberg, Germany, 2018.

26. Gudmundsson, O.; Nielsen, A.; Iversen, J. The effects of lowering the network temperatures in existing networks. In Proceedings of the 13th International Symposium on District Heating and Cooling, Copenhagen, Denmark, 3-4 September 2012.

27. Frederiksen, S.; Werner, S. District Heating and Cooling; Studentlitteratur: Lund, Sweden, 2013; ISBN 9789144085302. 